\title{
Spinal cord compression due to extramedullary hematopoiesis in patient with Beta thalassemia major
}

\author{
Eihab A. Subahi ${ }^{1}$ iD | Mohamed Abdelrazek $^{2} \mid$ Mohamed A. Yassin $^{3}$ (D)
}

\author{
${ }^{1}$ Department of Internal Medicine, Hamad \\ Medical Corporation, Doha, Qatar \\ ${ }^{2}$ Department of Radiology, Hamad Medical \\ Corporation, Doha, Qatar \\ ${ }^{3}$ Department of Medical Oncology, \\ National Center for Cancer Care and \\ Research, Hamad Medical Corporation, \\ Doha, Qatar

\section{Correspondence} \\ Eihab A. Subahi, Department of Internal \\ Medicine, Hamad Medical Corporation, \\ Doha, P.O 3050, Qatar. \\ Emails: ehabsubahi@yahoo.com; \\ ehabsubahi7@gamil.com \\ Funding information \\ This work was funded by Qatar National \\ Library.
}

\begin{abstract}
Extramedullary hematopoiesis can occur in patients with beta thalassemia major, which can lead to spinal cord compression. In such cases, the use of radiotherapy can be sufficient for the complete resolution of neurological symptoms.
\end{abstract}

\section{K E Y W O R D S}

extramedullary hematopoiesis, spinal cord compression, thalassemia

\section{1 | INTRODUCTION}

Extramedullary hematopoiesis is a rare disorder, defined as the appearance of hematopoietic elements outside the bone marrow or peripheral blood. The most common sites of it are the liver and spleen, but it has been documented in other organs such as the mediastinum, lymph nodes, breast, and central nervous system. It occurs as a compensatory mechanism for bone marrow dysfunction in severe thalassemia. We reported an 18-year-old male with beta thalassemia major who presented with mid thoracic to lower back pain progressive over 1 month associated with numbness in thighs, together with lower limb weakness and difficulty walking. He also mentioned having difficulty in passing urine. He received low-dose radiotherapy, which results in significant improvement in his symptoms.

Hemoglobinopathies constitute the commonest recessive monogenic disorders worldwide. They fall into two main groups: the thalassemia syndromes and the structural hemoglobin variants (abnormal hemoglobin). $\alpha, \beta$, and $\delta \beta$ thalassemia are the main types of thalassemia with clinical importance; the most frequent and clinically important structural hemoglobin variants are $\mathrm{HbS}, \mathrm{HbE}, \mathrm{HbC}$, and $\mathrm{HbD}$. The treatment of patients presents a substantial global disease burden. Variants of thalassemia and main abnormal hemoglobin interact to produce a wide range of clinical disorders of varying severity. ${ }^{1}$ From a clinical perspective, thalassemia syndromes were classified into transfusion-dependent thalassemia and nontransfusion-dependent thalassemia. ${ }^{2}$ Most of the complications of thalassemia result from iron overload with liver and heart being the main cause for morbidity and mortality. ${ }^{3}$ Other complications mainly endocrine like osteoporosis, ${ }^{4}$ diabetes, ${ }^{5}$ thyroid, ${ }^{6}$ hypogonadism, and fertility, ${ }^{7,8}$ as well as cortisol abnormalities. ${ }^{9}$ Patient with thalassemia should go for ALLO-SCT (allogeneic stem cell transplantation) if HLA identical sibling is available or to maintain transfusion and chelating therapy lifelong in the form of desferal, deferiprone, or deferasirox or its new film coated formula. ${ }^{10}$ 
T A B L E 1 Demonstrate patient investigations at the time of presentation

\begin{tabular}{|lll|}
\hline Test & Value & $\begin{array}{l}\text { Reference } \\
\text { range }\end{array}$ \\
\hline $\mathrm{WBC}$ & 5.1 & $4-10 \times 10^{3 /} \mu \mathrm{L}$ \\
\hline $\mathrm{Hb}$ & 8.6 & $13-17 \mathrm{gm} / \mathrm{dL}$ \\
\hline platelets & 213 & $150-$ \\
& & $400 \times 10^{3} /$ \\
& & $\mu \mathrm{L}$ \\
\hline Bilirubin total & 80.9 & $3.4-$ \\
& & $20.5 \mu \mathrm{mol} / \mathrm{L}$ \\
\hline Dicer bilirubin & 13.2 & $1.8-$ \\
& & $10.9 \mu \mathrm{mol} / \mathrm{L}$ \\
\hline Alkaline phosphatase & 147.2 & $59-164 \mathrm{U} / \mathrm{L}$ \\
\hline Alanine transaminase & 56.2 & $9-24 \mathrm{U} / \mathrm{L}$ \\
\hline Aspartate transaminase & 64 & $13-26 \mathrm{U} / \mathrm{L}$ \\
\hline Iron & 46.23 & $5.6-$ \\
& & $30.1 \mu \mathrm{mol} / \mathrm{L}$ \\
\hline Ferritin & 2345 & $23-70 \mathrm{mcg} / \mathrm{L}$ \\
\hline
\end{tabular}

The risk of neurologic compromise in this disease is in part due to the fact that extramedullary hematopoiesis within the spinal canal can result in the compression of neural structures. There have only been a few reports in the literature describing spinal cord compression by such a disease process. ${ }^{11,12}$

Treatment options have been described, including transfusion therapy, ${ }^{11,13}$ laminectomy, radiotherapy, ${ }^{12,14,15}$ and the use of fetal hemoglobin inducing agents that decrease the hematopoietic drive. However, the ideal management regimen remains controversial.

\section{2 | CASE PRESENTATION}

An 18-year-old male known to have beta thalassemia major on regular blood transfusion every 3 weeks (Figure 1). He is on deferasirox (iron chelator agent) but he is not compliant

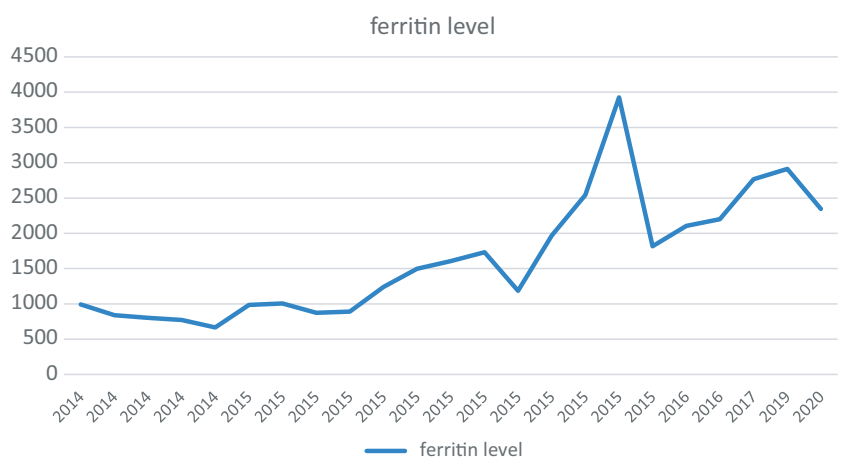

F I G URE 1 representing patient ferritin level since 2014 till the time of presentation with it and oral hydroxyurea $1000 \mathrm{mg}$ daily. He is presented to the emergency department with a history of midthoracic to lower back pain progressive over 1 month associated with numbness in both thighs, together with lower limb weakness and difficulty in walking. He also mentions having difficulty in passing urine. He denies any other symptoms and no history of trauma.

His laboratories showed hemoglobin $8.6 \mathrm{gm} / \mathrm{dl}$, leukocytes count, and platelet were normal. Totally, his bilirubin was $80.9 \mathrm{umol} / \mathrm{l}$ and direct bilirubin was $13.2 \mathrm{umol} / \mathrm{L}$, ALT $56.2 \mathrm{U} / \mathrm{L}$ and ALT $64 \mathrm{U} / \mathrm{L}$, and ferritin $2345 \mathrm{mcg} / \mathrm{L}$, other laboratories unremarkable (Table 1). On examination, he had a spastic gait, lower limb examination showed hyperreflexia with positive ankle clonus and plantar upgoing bilaterally, and strength in hip flexion was $4 / 5$ bilaterally otherwise 5/5 for the remaining muscles group, absent vibration and decrease sensation in lower limbs with no specific dermatome, mild spasticity more in the left leg, and PR showed decrease sensation and normal tone. Cranial nerves and upper limb examination both were normal.

MRI spine showed intraspinal posterior extramedullary epidural lobulated lesions extending from the lower border of the T2 vertebral body up to the T9 vertebral body. They demonstrate immediate to low T1WI signal intensity and dark T2WI signal intensity with mild heterogeneous postcontrast enhancement (Figure 2A and B). They are causing moderate-to-severe spinal canal stenosis and significant compression and anterior displacement as well as thinning of the spinal cord. There is intramedullary high T2WI signal intensity at the compressed segment of the spinal cord suggesting edema and/or myelomalacia. Similar intraspinal anterior epidural lesions are seen at the T7 and the T10 levels and seen extending through bilateral exiting neural foramina; left more than right (Figure 2D and E). Similar anterior intraspinal lesions are seen at the L5-S1 level (Figure 2C), demonstrating an interval increase in size, as compared to previous MRI lumbar spine done two years ago compromising the thecal sac. Impression was intraspinal epidural lobulated lesions causing significant neural compromise, and the appearances are highly suggestive of extramedullary hematopoiesis.

The patient is seen by the neurosurgery team, and they advise for radiotherapy before any surgical intervention for the following reasons, the extramedullary hematopoiesis tissue is radiosensitive beside that the lesion involves a long segment of the spinal column (almost from T2 to T9), so surgery will involve bone removal (hemilaminectomy) in all levels and may affect the stability of spinal column lastly. The Patient has weak fragile bones related to his general condition, and In case of instrumentation and fusion, there is high probability of failure and they suggest that in case of failure of radiotherapy they can offer the surgical option to the patient with major risks due to above mentioned reasons. 

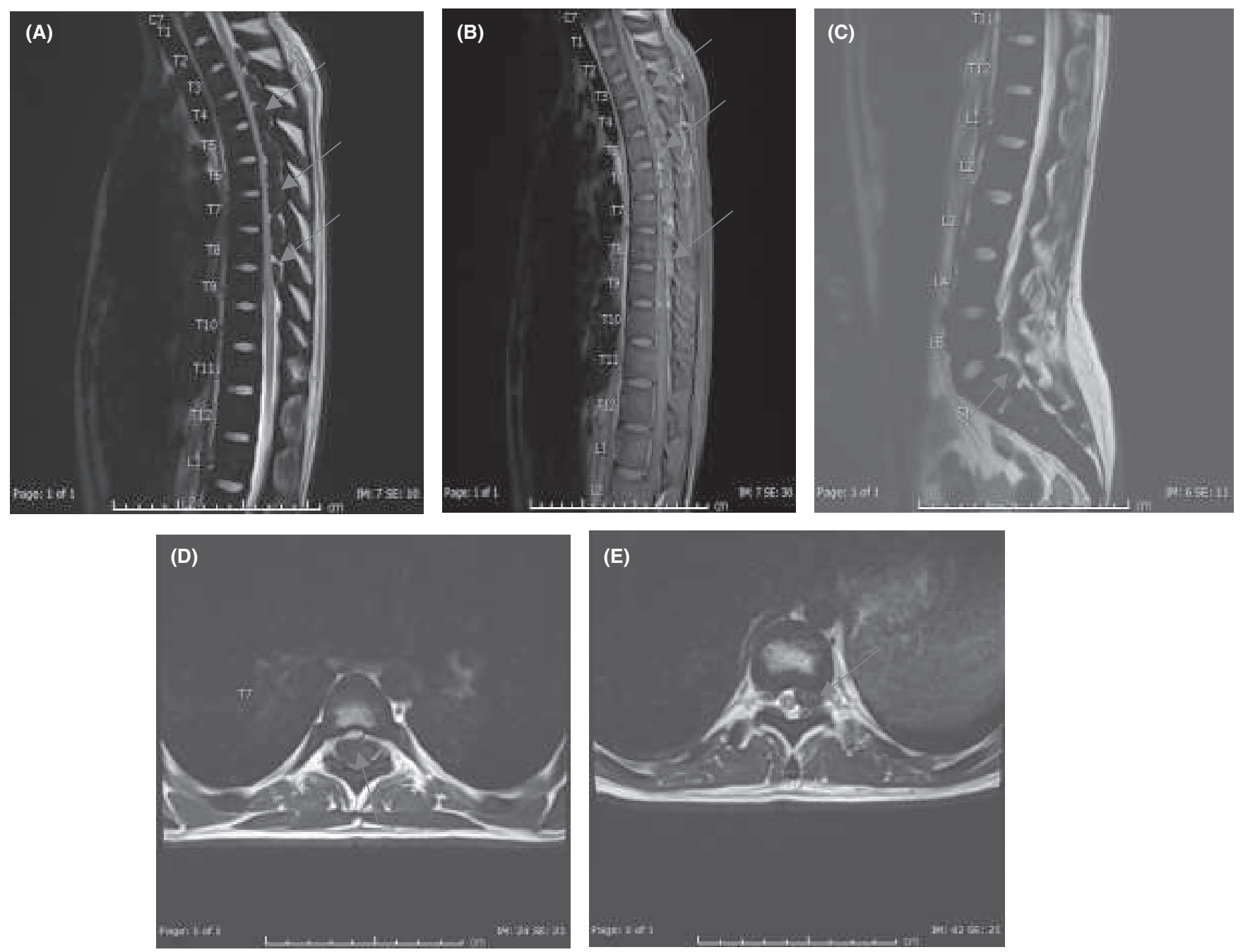

F I G URE 2 MRI spine of patient with thalassemia major. A, Sagittal T2 WI of Thoracic spine. B, Sagittal post contrast fat saturated T1 WI of Thoracic spine. C, Sagittal T2 WI of Lumbar spine. D, Axial T2 WI of Thoracic spine at T7 level. E, Axial T2 WI of Thoracic spine at T10. Multiple lobulated intraspinal epidural extramedullary masses are seen extending from lower border of T2 vertebral body down to T9 vertebral body, and they show low SI in T2 WI and mild heterogenous enhancement after intravenous contrast administration (Arrows in A \&amp;

B). Similar areas are noted At L5-S1 level in anterior intraspinal extramedullary space (Arrow in C). They cause anterior displacement and compression of the cord in thoracic spine (arrow in D at T7 level) and extend to left neural foramen (Arrow in E at T10 level). There is also diffuse low signal intensity of the bone marrow of thoracic and lumbar vertebra due to marrow conversion

Oncology radiotherapy saw the patient and decided to proceed to radiotherapy. The patient admitted to the hospital started on intravenous dexamethasone waiting for the radiotherapy, and he received a blood transfusion as well to improve his hemoglobin from 7.5 to $11.2 \mathrm{gm} / \mathrm{dL}$. Later on, an admission he received ten sessions of radiotherapy the dose was 2000 cGy received over 14 days with significant improvement in his weakness and other neurological symptoms.

\section{DISCUSSION}

Extramedullary hematopoiesis is a rare manifestation of thalassemia that was first described by Guizetti during an autopsy in $1912 .{ }^{16}$ Gatto was the first to describe spinal cord compression from the extramedullary overgrowth of the hematopoietic tissue. ${ }^{17}$ The diagnosis of the disease depends on symptoms that are confirmed by MRI finding. The male-to-female ratio for spinal cord compression by extramedullary mass was $5: 1$. Thoracic cord compression was seen primarily in the lower thoracic spine. ${ }^{11}$ Extramedullary hematopoiesis occurs in multiple blood disorders including thalassemia. The usual organ involvement includes the liver, spleen, and lymph nodes. The onset of neurologic symptoms in a patient with such underlying blood dyscrasias should prompt a high clinical suspicion for cord compression or thecal sac compression by an extramedullary hematopoietic process. The treatment modalities available to such patients are limited. Intervention options have included multiple blood 
transfusions to downregulate erythropoietin production, radiation therapy to stop the production of overgrown marrow tissue, surgical decompression, or a combination of any of the above. ${ }^{11,18}$ The relative benefit of one treatment over another has not been clearly established due to the infrequency of this disorder. The risks of surgical treatment include excessive bleeding in a patient with low hemoglobin and difficulty in transfusion due to antibodies and cardiopulmonary stress. The benefit of surgery includes the immediate resolution of compression and its symptoms upon decompression. Surgical decompression also provides a good histologic diagnosis. Lau et al report the case of a 28-year-old woman with cord compression in the thoracic spine who underwent surgical decompression with the immediate postoperative recovery of weakness. A complete resolution of symptoms had occurred at 2 months of follow-up. Multiple transfusions were also required to maintain the hemoglobin above $10 \mathrm{~g} / \mathrm{dl} .{ }^{18}$ Our patient was reviewed by neurosurgery initially but as mentioned before, surgery was decline and he offered low dose radiotherapy instate. The risks of radiotherapy in the treatment of cord compression in such patients include the lack of any tissue for histological diagnosis and the risks involved with radiation exposure. The benefits include ready availability, effectiveness in the resolution of symptoms in a short period of time, and reduction of local recurrence. ${ }^{19}$ Abassioun and Amir-Jamshidiin 1982 reported the case of a 15-year-old female who was paraparetic with long tract signs. ${ }^{20}$ The patient's symptoms resolved after $1500 \mathrm{cGy}$ of radiation in five treatments with only residual right sustained clonus. Kaufman et al also reported two patients with thalassemia who underwent radiation therapy with resolution of symptoms in 3-7 days. ${ }^{19}$ Singhal et al in a review of the literature argue that radiation therapy should be the primary modality for treatment, and surgical intervention and transfusion should be reserved for the recurrent cases postradiation. ${ }^{21}$ The radiation dosage used mostly in different treatment protocols included a range between 1000 and $3000 \mathrm{cGy}$. Our patient received $2000 \mathrm{cGy}$ for ten sessions with good response evident by resolution in his symptoms and with no complications.

\section{4 | CONCLUSION}

Extramedullary erythropoiesis is a natural tissue response to a low hemoglobin count in patients with thalassemia. This may cause neurologic conditions such as spinal cord compression. Rapid diagnosis and treatment are important to prevent further neurological injury and improve functional outcome in such patients. For the previously mentioned reasons and by reviewing the literature, we conclude that in patients with thalassemia and spinal cord compression, radiation can be effective in the resolution of the symptoms.

\section{ACKNOWLEDGMENTS}

The authors would like to acknowledge the internal medicine residency program and Qatar National Library for their support. Published with written consent of the patient.

\section{CONFLICT OF INTEREST}

None declared.

\section{AUTHOR CONTRIBUTIONS}

Dr Eihab A. Subahi and Dr Mohamed A. Yassin: wrote and edited the manuscript. Dr Mohamed Abdelrazek: reviewed the MRI images and provided us with labeled images.

\section{STATEMENT OF ETHICS}

The patient consented to the publication of his case.

\section{DATA AVAILABILITY STATEMENT}

The data that support the findings of this study are available from the corresponding author upon reasonable request.

\section{ORCID}

Eihab A. Subahi iD https://orcid.org/0000-0001-9190-2891

Mohamed A. Yassin iD https://orcid. org/0000-0002-1144-8076

\section{REFERENCES}

1. De Sanctis V, Kattamis C, Canatan D, et al. $\beta$-thalassemia distribution in the old world: an ancient disease seen from a historical standpoint. Mediterranean J Hematol Infect Dis. 2017;9(1):e2017018. http://www.mjhid.org/index.php/mjhid/artic le/view/2017.018

2. Kanbour I, Chandra P, Soliman A, et al. Severe liver iron concentrations (LIC) in 24 patients with $\beta$-thalassemia major: Correlations with serum ferritin, liver enzymes and endocrine complications. Mediterr J Hematol Infect Dis. 2018.10(1):2018062. http://www. mjhid.org/index.php/mjhid/article/view/2018.062

3. Soliman AT, Yassin M, Al Yafei F, et al. Longitudinal study on liver functions in patients with thalassemia major before and after deferasirox (DFX) therapy. Mediterr J Hematol Infect Dis. 6(1):e2014025.

4. Yassin MA, Soliman AT, De Sanctis V, Abdelrahman MO, Aziz Bedair EM, Abdelgawad M. Effects of the anti-receptor activator of nuclear factor kappa B ligand denusomab on beta thalassemia major-induced osteoporosis. Indian J Endocrinol Metab. 2014;18(4):546.

5. Soliman A, Yasin M, El-Awwa A, De Sanctis V. Detection of glycemic abnormalities in adolescents with beta thalassemia using continuous glucose monitoring and oral glucose tolerance in adolescents and young adults with $\beta$-thalassemia major: Pilot study. Indian J Endocrinol Metab. 2013;17(3):490.

6. De VS, Soliman A, Candini G, Campisi S, Anastasi S, Iassin M. High prevalence of central hypothyroidism in adult patients with $\beta$-thalassemia major. Georgian Med News. 2013;222:88-94. 
7. De SV, Elsedfy H, Soliman AT, et al. Acquired hypogonadotropic hypogonadism $(\mathrm{AHH})$ in thalassaemia major patients: An underdiagnosed condition? Mediterr J Hematol Infect Dis. 2016;8(1):e2016001.

8. Soliman A, Yasin M, El-Awwa A, Osman M, De Sanctis V. Acute effects of blood transfusion on pituitary gonadal axis and sperm parameters in adolescents and young men with thalassemia major: A pilot study. Fertil Steril. 2012;98(3):638-643.

9. Soliman A, Yassin M, Majuid NMSA, Sabt A, Abdulrahman M, De Sanctis V. Cortisol response to low dose versus standard dose (back-to-back) adrenocorticotrophic stimulation tests in children and young adults with thalassemia major. Indian J Endocrinol Metab. 2013;17(6):1046.

10. Yassin MA, Soliman AT, De Sanctis V, et al. Jadenu ${ }^{\circledR}$ substituting Exjade ${ }^{\circledR}$ in iron overloaded $\beta$-thalassemia major (BTM) patients: A preliminary report of the effects on the tolerability, serum ferritin level, liver iron concentration and biochemical profiles. Mediterr J Hematol Infect Dis. 2018;10(1):e2018064. http://www.mjhid.org/ index.php/mjhid/article/view/2018.064

11. Issaragrisil S, Piankijagum A, Wasi P. Spinal cord compression in thalassemia: report of 12 cases and recommendations for treatment. Arch Intern Med. 1981;141(8):1033-1036.

12. Luyendijk W, Went L, Schaad HDG. Spinal cord compression due to extramedullary hematopoiesis in homozygous thalassemia: case report. J Neurosurg. 1975;42(2):212-216.

13. Chehal A, Aoun E, Koussa S, Skoury H, Koussa S, Taher A. Hypertransfusion: a successful method of treatment in thalassemia intermedia patients with spinal cord compression secondary to extramedullary hematopoiesis. Spine. 2003;28(13):E245-E249.

14. Stahl SM, Ellinger G, Baringer JR. Progressive myelopathy due to extramedullary hematopoiesis: Case report and review of the literature. Ann Neurol. 1979;5(5):485-489.
15. Luitjes WF, Braakman R, Abels J. Spinal cord compression in a new homozygous variant of beta-thalassemia. Case report. $J$ Neurosurg. 1982;57(6):846-848.

16. Elbers H, Stadt JV, Wagenaar SS. Tumor-simulating thoracic extramedullary hematopoiesis. Ann Thorac Surg. 1980;30(6):584-587.

17. Mancuso P, Zingale A, Basile L, Chiaramonte I, Tropea R. Cauda equina compression syndrome in a patient affected by thalassemia intermedia: complete regression with blood transfusion therapy. Child's Nerv Syst. 1993;9(7):440-441.

18. Lau SK, Chan CK, Chow YYN. Cord compression due to extramedullary hemopoiesis in a patient with thalassemia. Spine. 1994;19(21):2467-2470.

19. Kaufmann T, Coleman M, Giardina P, Nisce LZ. The role of radiation therapy in the management of hematopoietic neurologic complications in thalassemia. Acta Haematol. 1991;85(3):156-159.

20. Abbassioun K, Amir-Jamshidi A. Curable paraplegia due to extradural hematopoietic tissue in thalassemia. Neurosurgery. 1982;11(6):804-807.

21. Singhal $S$, Sharma $S$, Dixit $S$, et al. The role of radiation therapy in the management of spinal cord compression due to extramedullary haematopoiesis in thalassaemia. J Neurol Neurosurg Psychiatry. 1992;55(4):310-312.

How to cite this article: Subahi EA, Abdelrazek M, Yassin MA. Spinal cord compression due to extramedullary hematopoiesis in patient with Beta thalassemia major. Clin Case Rep. 2021;9:405-409. https://doi.org/10.1002/ccr3.3542 